\title{
ANÁLISE DO PERFIL LONGITUDINAL E APLICAÇÃO DE ÍNDICE DE HACK NO CÓRREGO RICO NO MUNICÍPIO DE PARACATU - MG
}

\author{
Matheus dos Santos Borges ${ }^{(a)}$, Kamila Cristina Silva ${ }^{(b)}$ \\ Graduando em Geografia, Instituto de Geografia/Geografia, Universidade Federal de Uberlândia, borgesms@ufu.br \\ Graduanda em Geografia, Instituto de Geografia/Geografia, Universidade Federal de Uberlândia, \\ kmilicrys@ hotmail.com
}

\section{EIXO: BACIAS HIDROGRÁFICAS E RECURSOS HÍDRICOS: ANÁLISE, PLANEJAMENTO E GESTÃO}

\begin{abstract}
Resumo
Partindo do entendimento que os cursos d'água são os principais modeladores do relevo, ajustando-se a qualquer modificação dos processos deformativos, torna-se uma importante ferramenta de estudo para análises geomorfológicas, especialmente àquelas que analisam os parâmetros morfométricos, tais como o Índice de Hack. Sendo assim o presente trabalho compreende em apresentar os resultados encontrados na análise longitudinal, com a execução do Índice de Hack e análise Litológica no canal fluvial do Córrego Rico que se encontra na microrregião de Paracatu Minas Gerais, utilizando softwares simples, como o Google Earth, LibreOffice e ArcGis.
\end{abstract}

Palavras chave: Índice de Hack, Perfil Longitudinal, Litologia, Córrego Rico, Google Earth.

\section{Indrodução}

A Geomorfologia tem como objetivo explicar as dinâmicas dos processos que envolvem as formações de relevo e sua evolução. Assim, a área de atuação da Geomorfologia inclui estudos que se utilizam de outras disciplinas, como exemplo a Geologia, Hidrografia, Climatologia, entre outras. As estruturas formadas na superfície terrestre, estabelece a forma geométrica local, sendo rios os modeladores do relevo e, em conjunto com ações climáticas e outros fatores, resultam nas paisagens atuais.

Sendo as formas de relevo o objeto de estudo da Geomorfologia, criaram-se vários métodos de análise para compreender todos os processos envolvidos, dentre eles está o Índice de Hack ou Índice SL (relação slope vs. length), método proposto por Hack 1973, que permite analisar a relação declividade e extenção do relevo e comparar com a estrutura de um canal fluvial.

Etchebehere (2004) aplica o índice SL, onde ele chama de RDE (Relação Declividade Extensão) para detecção de áreas de deformações neotectônicas na Bacia do rio Peixe, em São Paulo, comparando com o perfil longitudinal, resultando que os atributos que saiam da média tinha grande relação nos pontos de rupturas no perfil. 


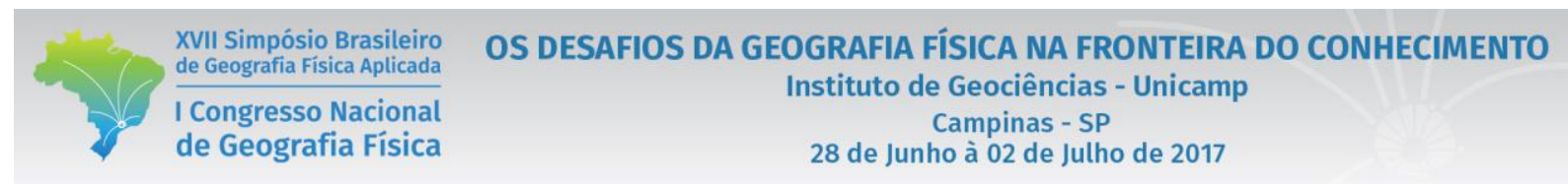

Os cursos d'água buscam um equilíbrio, que pode ser observado na relação entre a capacidade do rio em carregar sedimentos e em escavar seu vale (SOUZA 2011). Essas caracteristicas os tornam apropriados no reconhecimento de áreas estáveis e instáveis. Nesse sentido, a utilização de técnicas morfométricas as quais se utilizam medidas relacionadas aos perfis dos cursos d'água, como o Índice SL, apresentam grande potencial para a identificação de áreas de deformações.

O objetivo deste trabalho é aplicar o Índice de Hack no Córrego Rico para a identificação de eventuais anomalias do relevo, como setores de alteração bruta de altitude, como ruptura e deformações do canal por diferença geologica e obter dados para organizar, em forma de graficos e tabelas, informações dessas irregularidades para caracterizar o canal fluvial da bacia da área estudada, utilizando recursos e ferramentas simples.

A área analisada se localiza na microrregião de Paracatu, limitado à mesorregião Noroeste do Estado de Minas Gerais. Corresponde à bacia hidrográfica do Corrego Rico, cujo sua foz é o Rio Paracatu pertencente à Bacia do Rio São Francisco. Sua extenão é de aproximadamente 102 quilômetros (Figura 1).

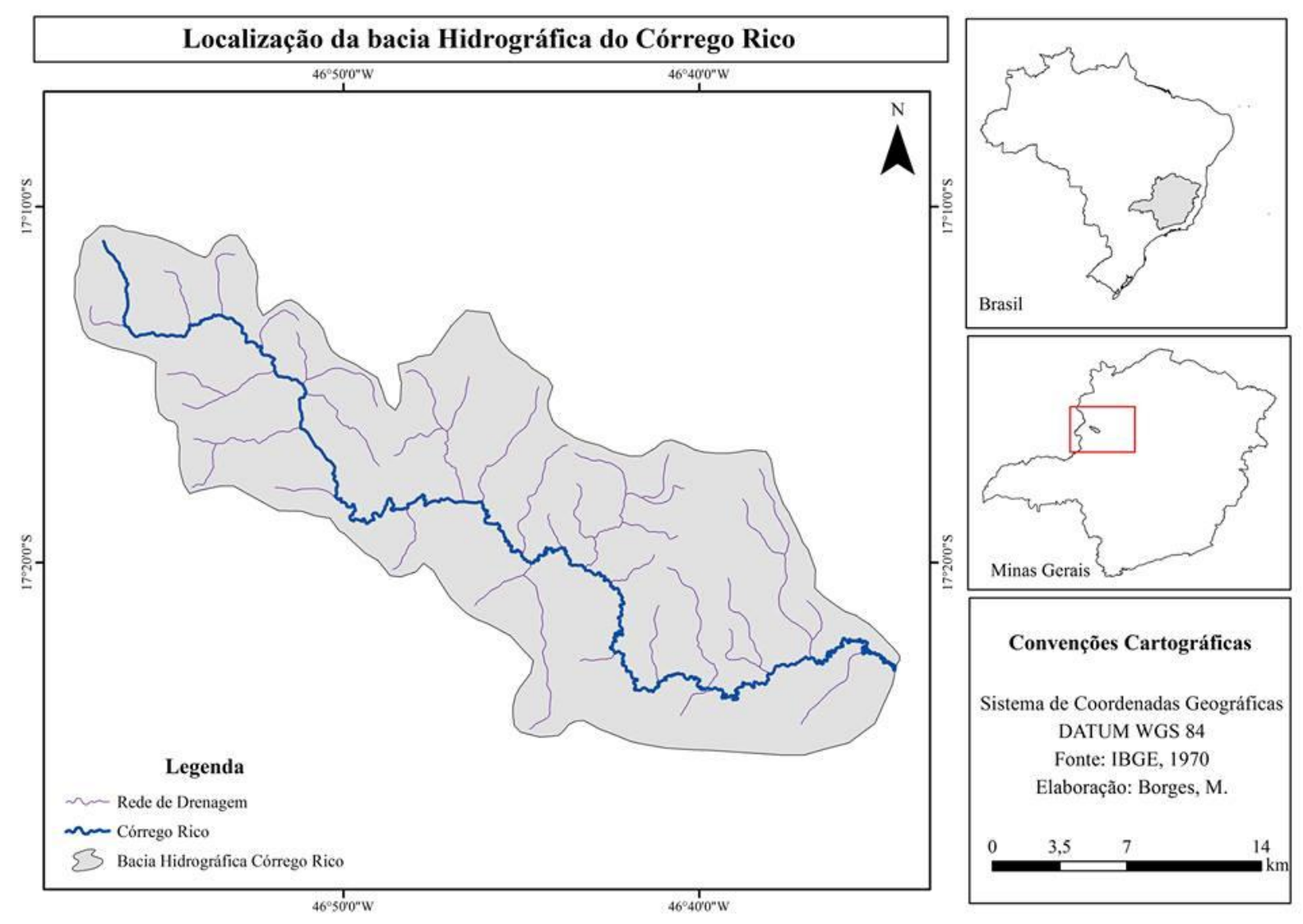

Figura 1: Localização da Bacia Hidrográfica do Córrego Rico 


\section{Fundamentação Teórica}

Geomorfologia endente-se por uma ciência que estuda a geometria da Terra. Ela busca compreender os processos que envolvem a formação do relevo e como elas evoluem. Segundo Marques (2013), o objeto de estudo da Geomorfologia são as formas de relevo, e para obter uma compreensão plena do que as formas de relevo significam e representam, é necessário considerar a existência e o funcionamento dos processos que envolvem sua gênese e a evolução de sua forma.

Penteado (1983), diz que a Geomorfologia é uma ciência da Terra, equivalente às outras geociências, têm seus próprios princípios fundamentais, que a conduz descrever, classificar e explicar. Seu campo de estudo envolve, também, toda a superfície de contato com a parte sólida do globo, a litosfera e formas de relevo, que é o reflexo do equilíbrio entre todos os processos endógenos e exógenos, tornando-se muito dinâmica.

Para Christofoletti (1980), as formas só existem porque foram esculpidas por ações de um processo ou conjunto de processos, ou seja, há uma relação forte entre o relevo e seus processos; sendo assim, o estudo de ambos deve ser o objetivo central da Geomorfologia. Os processos morfogenéticos, que representam as dinâmicas externas sobre as vertentes, trazem informações de hierarquia teórica e prática.

Os rios são os meios mais importantes entre os processos morfogenéticos, pois são os agentes que modificam o relevo de forma significativa. De acordo com Cunha 2013 a Geomorfologia Fluvial é uma ramificação da geomorfologia que integra estudos de cursos d'água e de bacias hidrográficas, representando um setor de destaque, pois os cursos d'água têm uma dinâmica intensa, que sempre estão em constante alteração.

O estudo das formas de relevo através de cursos d'água se dá pela análise de seu perfil longitudinal, onde são observados processos capazes de explicar tais formas.

O perfil longitudinal de um rio mostra a sua declividade, ou gradiente, sendo a representação visual da relação entre a altimetria e o comprimento de determinado curso de água, para as diversas localidades situadas entre a nascente e a foz. Para muitos rios, a curva representativa dessa relação tem a forma parabólica e o perfil típico é côncavo para o céu, com declividades maiores em direção da nascente e com valores cada vez mais suaves em direção de jusante (CHRISTOFOLETTI, 1981)

Segundo Hack (1960), as redes de drenagem possuem propriedades geométricas que podem ser descritas quantitativamente. Morfometria nada mais é do que essa "propriedade" que caracteriza quantitativamente o relevo. As tecnicas morfométricas auxiliam no fornecimento de informações importantes sobre a litologia e geomorfologia de uma vertente, além de obter uma noção melhor sobre o comportamento hidrológico e um acompanhamento dinâmico relacionado aos cursos d'àgua. 
“Os cursos d'água são os elementos mais sensíveis às mudanças tectônicas crustais, respondendo de imediato aos processos deformativos" (Etchebehere et al, 2004). De acordo com esse fato, os rios são muito ultilizados em estudos geomorfológicos nas áreas fluviais. Há vários métodos na aplicação dos índices morfométricos na comparação de parâmetros que permitem analisar deformações estruturais e litológicas e que analisa o perfil longitudinal de um canal fluvial. Um desses métodos, que passou a ser mais facil e ágil de se produzir com a utilização de meios digitais, é o índice de Hack.

Para Hack, as formas de relevo e os depósitos superficiais possuem uma íntima relação com a estrutura geológica (litologia) e mecanismos de intemperização, embora deixando transparecer maior valorização da primeira. $\mathrm{O}$ autor verificou que a declividade dos canais fluviais diminui com o comprimento do rio e varia em função do material que está sendo escavado (HACK, J. T. 1965 apud CASSETI, V. 2005)

O Índice de Hack vem como instrumento para comparar a declividade com o tipo de estrutura presente na área da bacia do canal fluvial. Nele temos a possibilidade de analisar seu perfil longitudinal, sua declividade, sinuosidade e saber sua dinâmica através das diferênças topográficas encontradas.

\section{Metodologia}

O precedimento dessa pesquisa consiste em um trabalho de gabinete, pois as tecnologias disponíveis hoje nos permite a realização de cálculos altimétricos e elaboração de mapas sem a necessidade de ir a campo, tornando-a acessível e um método de baixo custo.

A realização do Índice SL consiste na aplicação da formula explicada por Polzin (2008):

A fórmula consiste na diferença altimétrica entre dois pontos extremos de um segmento ao longo do curso d'água $(\Delta \mathrm{h})$, dividida pela projeção tangencial da extensão do referido segmento $(\Delta \mathrm{l})$ e multiplicada pelo comprimento total do curso d'água $(\mathrm{L})$ a montante do ponto para o qual o índice está sendo calculado. (POLZIN, 2008)

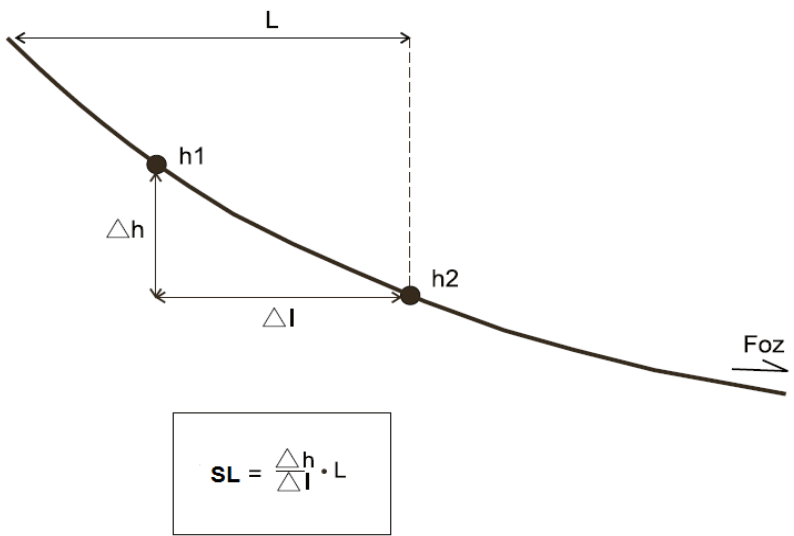

Figura 2: Esquema Proposto por Hack. Fonte: ETCHEBEHERE, 2004 


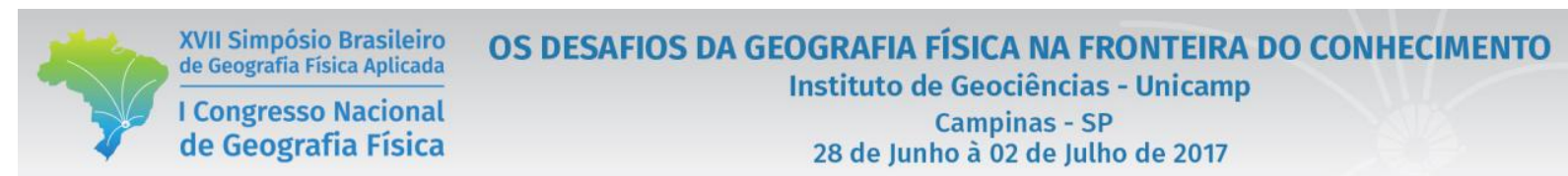

Foi utilizado o software Google Earth para a digitalização do canal do Córrego Rico. O programa permite visualizar a diferença altimétrica de dois pontos $(\Delta \mathrm{h})$ e a projeção tangencial da extenção $(\Delta \mathrm{l})$ do trecho medido (Figura 3). O canal foi dividido em 51 partes, cada parte contendo 2 quilometros de comprimento (L), desde a nascente até sua foz, para uma melhor análise do perfil longitudinal e de elevação de cada trecho.

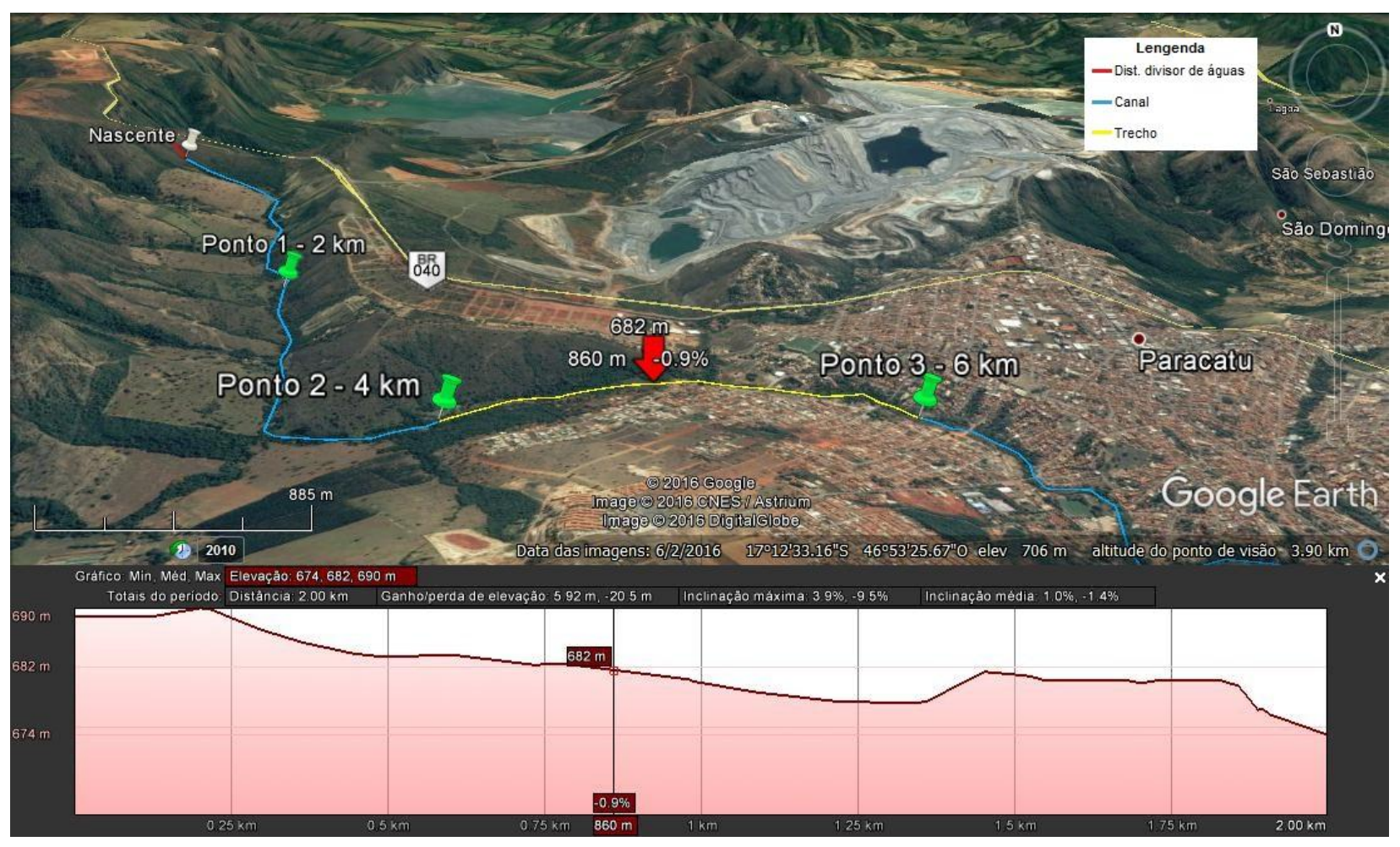

Figura 3: Aplicação do Índice SL no software Google Earth

Como visto na figura acima, é evidente alguns erros no Google Earth a respeito do perfil de elevação pois há uma discordância entre os valores de altitude com o terreno onde se passa o rio, resultando em uma elevação no canal fluvial. Isso ocorre pois existem matas ciliades de altitudes elevadas em relação ao solo ou ao próprio canal que o programa não reconhece. Para resolver esse problema foi analizado apenas a elevação máxima e mínima do trecho, para o cálculo da diferença de altitude de cada trecho, obtendo o dado necessário para aplicação do índice (tabela 1).

A partir dos dados adquiridos no Google Earth, uma tabela foi elaborada para comparação dos parametros de cada trecho do canal e a realização dos cálculos altimétricos do Índice SL para cada trecho de $2 \mathrm{~km}$, ultilizando a ferramenta LibreOffice 5.3 .0 (tabela 1). Os resultados dos cálculos propiciou o estabelecimento da comparação de cada trecho segundo a estrutura do canal. 


\begin{tabular}{|c|c|c|c|c|c|c|c|c|c|c|}
\hline \multirow[b]{2}{*}{$A$} & \multicolumn{2}{|c|}{$\begin{array}{l}\text { XVII Simpósio Brasileiro } \\
\text { de Geografia Fisica Aplicada } \\
\text { I Congresso Nacional } \\
\text { de Geografia Física }\end{array}$} & \multicolumn{8}{|c|}{$\begin{array}{l}\text { OS DESAFIOS DA GEOGRAFIA FISICA NA FRONTEIRA DO CONHECIMENTO } \\
\text { Instituto de Geociências - Unicamp }\end{array}$} \\
\hline & $\mathrm{B}$ & $\mathrm{C}$ & $\mathrm{D}$ & $E$ & $\mathrm{~F}$ & $\mathrm{G}$ & $\mathrm{H}$ & 1 & $\mathrm{~J}$ & $\mathrm{~K}$ \\
\hline \multirow[t]{2}{*}{$\begin{array}{l}\text { Número } \\
\text { do trecho }\end{array}$} & $\begin{array}{c}\text { Distância da } \\
\text { nascente ao } \\
\text { divisor }\end{array}$ & $\begin{array}{l}\text { Cálculo da } \\
\text { Inclinação }\end{array}$ & $\begin{array}{c}\text { Cumprimento do } \\
\text { Trecho }(\Delta l)\end{array}$ & $\begin{array}{c}\text { Somatória dos } \\
\text { Trechos }\end{array}$ & $\begin{array}{c}\text { Metade } \\
\text { do Trecho }\end{array}$ & $\begin{array}{c}\text { Valor } \\
\text { trechos (L) }\end{array}$ & $\begin{array}{l}\text { Altura } \\
\text { Máxima }\end{array}$ & $\begin{array}{l}\text { Altura } \\
\text { Minima }\end{array}$ & $\begin{array}{l}\text { Diferença de } \\
\text { Altura }(\Delta h)\end{array}$ & $\mathrm{SL}$ \\
\hline & Fixo (m) & $J / D$ & Medido (m) & D+Eacima & $D / 2$ & $\mathrm{E} 1+\mathrm{F} 2+\mathrm{B} 2$ & Medido & Medido & $\mathrm{H}-\mathrm{I}$ & $C^{*} \mathrm{G}$ \\
\hline 1 & 248,79 & 0,0425 & 2000 & 2000 & 1000 & 1248,79 & 813 & 728 & 85 & 53,07358 \\
\hline 2 & 248,79 & 0,0205 & 2000 & 4000 & 1000 & 3248,79 & 728 & 687 & 41 & 66,6002 \\
\hline 3 & 248,79 & 0,0065 & 2000 & 6000 & 1000 & 5248,79 & 687 & 674 & 13 & 34,11714 \\
\hline 4 & 248,79 & 0,003 & 2000 & 8000 & 1000 & 7248,79 & 674 & 668 & 6 & 21,74637 \\
\hline 5 & 248,79 & 0,0035 & 2000 & 10000 & 1000 & 9248,79 & 668 & 661 & 7 & 32,37077 \\
\hline 6 & 248,79 & 0,001 & 2000 & 12000 & 1000 & 11248,79 & 661 & 659 & 2 & 11,24879 \\
\hline 7 & 248,79 & 0,0045 & 2000 & 14000 & 1000 & 13248,79 & 659 & 650 & 9 & 59,61956 \\
\hline 8 & 248,79 & 0,002 & 2000 & 16000 & 1000 & 15248,79 & 650 & 646 & 4 & 30,49758 \\
\hline 9 & 248,79 & 0,0035 & 2000 & 18000 & 1000 & 17248,79 & 646 & 639 & 7 & 60,37077 \\
\hline 10 & 248,79 & 0,001 & 2000 & 20000 & 1000 & 19248,79 & 639 & 637 & 2 & 19,24879 \\
\hline 11 & 248,79 & 0,001 & 2000 & 22000 & 1000 & 21248,79 & 637 & 635 & 2 & 21,24879 \\
\hline 12 & 248,79 & 0,0025 & 2000 & 24000 & 1000 & 23248,79 & 635 & 630 & 5 & 58,12198 \\
\hline 13 & 248,79 & 0,002 & 2000 & 26000 & 1000 & 25248,79 & 630 & 626 & 4 & 50,49758 \\
\hline 14 & 248,79 & 0,0055 & 2000 & 28000 & 1000 & 27248,79 & 626 & 615 & 11 & 149,8683 \\
\hline 15 & 248,79 & 0,0015 & 2000 & 30000 & 1000 & 29248,79 & 615 & 612 & 3 & 43,87319 \\
\hline 16 & 248,79 & 0,003 & 2000 & 32000 & 1000 & 31248,79 & 612 & 606 & 6 & 93,74637 \\
\hline 17 & 248,79 & 0,0055 & 2000 & 34000 & 1000 & 33248,79 & 606 & 595 & 11 & 182,8683 \\
\hline 18 & 248,79 & 0,0005 & 2000 & 36000 & 1000 & 35248,79 & 595 & 594 & 1 & 17,6244 \\
\hline 19 & 248,79 & 0,0005 & 2000 & 38000 & 1000 & 37248,79 & 594 & 593 & 1 & 18,6244 \\
\hline 20 & 248,79 & 0,001 & 2000 & 40000 & 1000 & 39248,79 & 593 & 591 & 2 & 39,24879 \\
\hline 21 & 248,79 & 0,005 & 2000 & 42000 & 1000 & 41248,79 & 591 & 581 & 10 & 206,244 \\
\hline 22 & 248,79 & 0,002 & 2000 & 44000 & 1000 & 43248,79 & 581 & 577 & 4 & 86,49758 \\
\hline 23 & 248,79 & 0,0015 & 2000 & 46000 & 1000 & 45248,79 & 577 & 574 & 3 & 67,87319 \\
\hline 24 & 248,79 & 0,001 & 2000 & 48000 & 1000 & 47248,79 & 574 & 572 & 2 & 47,24879 \\
\hline 25 & 248,79 & 0,0005 & 2000 & 50000 & 1000 & 49248,79 & 572 & 571 & 1 & 24,6244 \\
\hline 26 & 248,79 & 0,0005 & 2000 & 52000 & 1000 & 51248,79 & 571 & 570 & 1 & 25,6244 \\
\hline 27 & 248,79 & 0,001 & 2000 & 54000 & 1000 & 53248,79 & 570 & 568 & 2 & 53,24879 \\
\hline 28 & 248,79 & 0,001 & 2000 & 56000 & 1000 & 55248,79 & 568 & 566 & 2 & 55,24879 \\
\hline 29 & 248,79 & 0,001 & 2000 & 58000 & 1000 & 57248,79 & 566 & 564 & 2 & 57,24879 \\
\hline 30 & 248,79 & 0,003 & 2000 & 60000 & 1000 & 59248,79 & 564 & 558 & 6 & 177,7464 \\
\hline 31 & 248,79 & 0,002 & 2000 & 62000 & 1000 & 61248,79 & 558 & 554 & 4 & 122,4976 \\
\hline 32 & 248,79 & 0,001 & 2000 & 64000 & 1000 & 63248,79 & 554 & 552 & 2 & 63,24879 \\
\hline 33 & 248,79 & 0,0005 & 2000 & 66000 & 1000 & 65248,79 & 552 & 551 & 1 & 32,6244 \\
\hline 34 & 248,79 & 0,0005 & 2000 & 68000 & 1000 & 67248,79 & 551 & 550 & 1 & 33,6244 \\
\hline 35 & 248,79 & 0,001 & 2000 & 70000 & 1000 & 69248,79 & 550 & 548 & 2 & 69,24879 \\
\hline 36 & 248,79 & 0,0005 & 2000 & 72000 & 1000 & 71248,79 & 548 & 547 & 1 & 35,6244 \\
\hline 37 & 248,79 & 0,0035 & 2000 & 74000 & 1000 & 73248,79 & 547 & 540 & 7 & 256,3708 \\
\hline 38 & 248,79 & 0,0025 & 2000 & 76000 & 1000 & 75248,79 & 540 & 535 & 5 & 188,122 \\
\hline 39 & 248,79 & 0,0015 & 2000 & 78000 & 1000 & 77248,79 & 535 & 532 & 3 & 115,8732 \\
\hline 40 & 248,79 & 0,0005 & 2000 & 80000 & 1000 & 79248,79 & 532 & 531 & 1 & 39,6244 \\
\hline 41 & 248,79 & 0 & 2000 & 82000 & 1000 & 81248,79 & 531 & 531 & 0 & 0 \\
\hline 42 & 248,79 & 0 & 2000 & 84000 & 1000 & 83248,79 & 531 & 531 & 0 & 0 \\
\hline 43 & 248,79 & 0,001 & 2000 & 86000 & 1000 & 85248,79 & 531 & 529 & 2 & 85,24879 \\
\hline 44 & 248,79 & 0,0005 & 2000 & 88000 & 1000 & 87248,79 & 529 & 528 & 1 & 43,6244 \\
\hline 45 & 248,79 & 0,0005 & 2000 & 90000 & 1000 & 89248,79 & 528 & 527 & 1 & 44,6244 \\
\hline 46 & 248,79 & 0,001 & 2000 & 92000 & 1000 & 91248,79 & 527 & 525 & 2 & 91,24879 \\
\hline 47 & 248,79 & 0,001 & 2000 & 94000 & 1000 & 93248,79 & 525 & 523 & 2 & 93,24879 \\
\hline 48 & 248,79 & 0,0025 & 2000 & 96000 & 1000 & 95248,79 & 523 & 518 & 5 & 238,122 \\
\hline 49 & 248,79 & 0 & 2000 & 98000 & 1000 & 97248,79 & 518 & 518 & 0 & 0 \\
\hline 50 & 248,79 & 0,001 & 2000 & 100000 & 1000 & 99248,79 & 518 & 516 & 2 & 99,24879 \\
\hline 51 & 248,79 & 0,0005 & 2156 & 102156 & 1078 & 101326,79 & 516 & 515 & 1 & 46,99758 \\
\hline
\end{tabular}

Tabela 1: Organização dos Dados e Cálculos do Índice SL 
A metodologia para obtenção de dados e elaboração da tabela está de acordo com o método proposto por Cooley (2015) vista na figura 4.

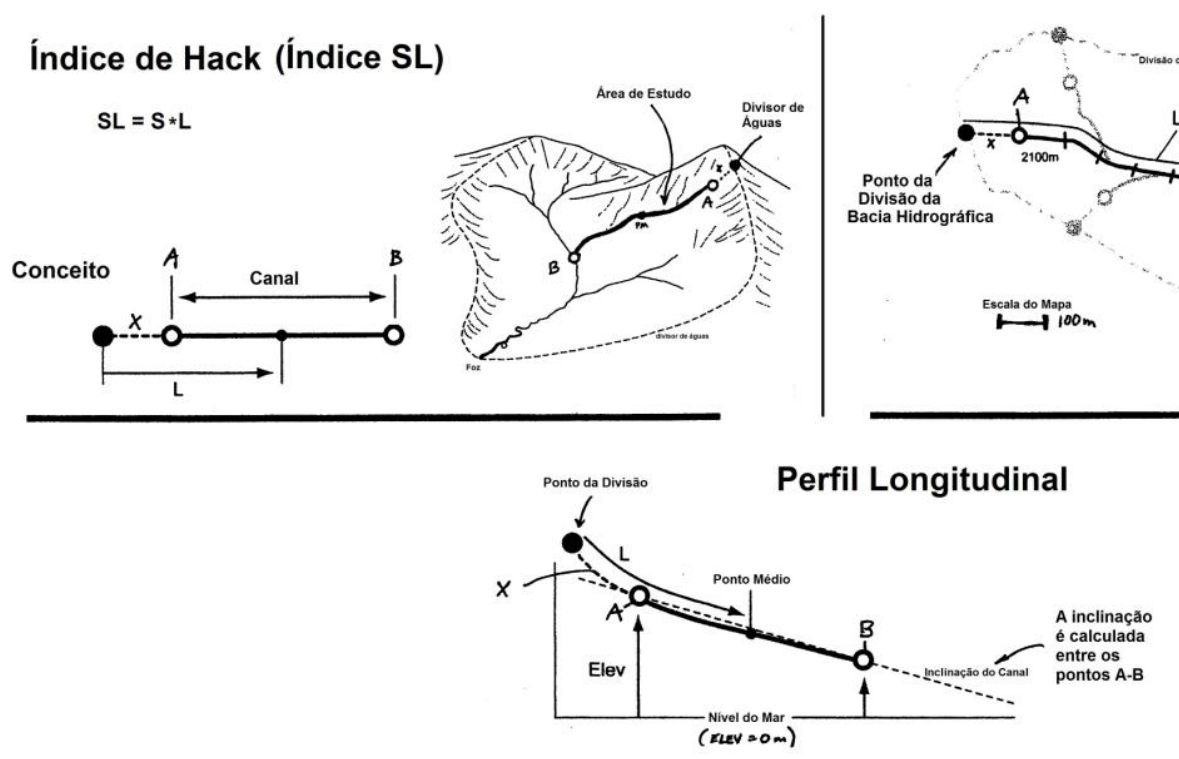

Figura 4: Adaptação do Índice de Hack proposto por Cooley. Fonte: COOLEY, 2015

A ferramenta de geoprocessamento ArcGis ver. 10.2.2, foi utilizada na elaboração dos mapas. Com ela foi permitido observar a litologia que abrange a bacia do rio estudado, segundo CODEMIG 2014, e analisar onde há uma maior expressividade do nível do Índice SL em seu perfil longitudinal.

\section{Resultados}

A bacia do córrego passa por dois grandes grupos litológicos, tanto sua nascente como a cidade de Paracatu MG, se situam sob a estrutura do Grupo Canastra, na Formação Paracatu, cujas rochas da área são metamórficas. Logo após o rio fica sob o Grupo Vazante, passando primeiro na Formação Serra da Lapa em meio urbano, depois na Formação Serra do Poço Verde e Formação Serra do Garrote, sendo que as rochas das três são sedimentares. Por fim, chega na área de Depósitos Aluviais antes de chegar à foz (Figura 5). 


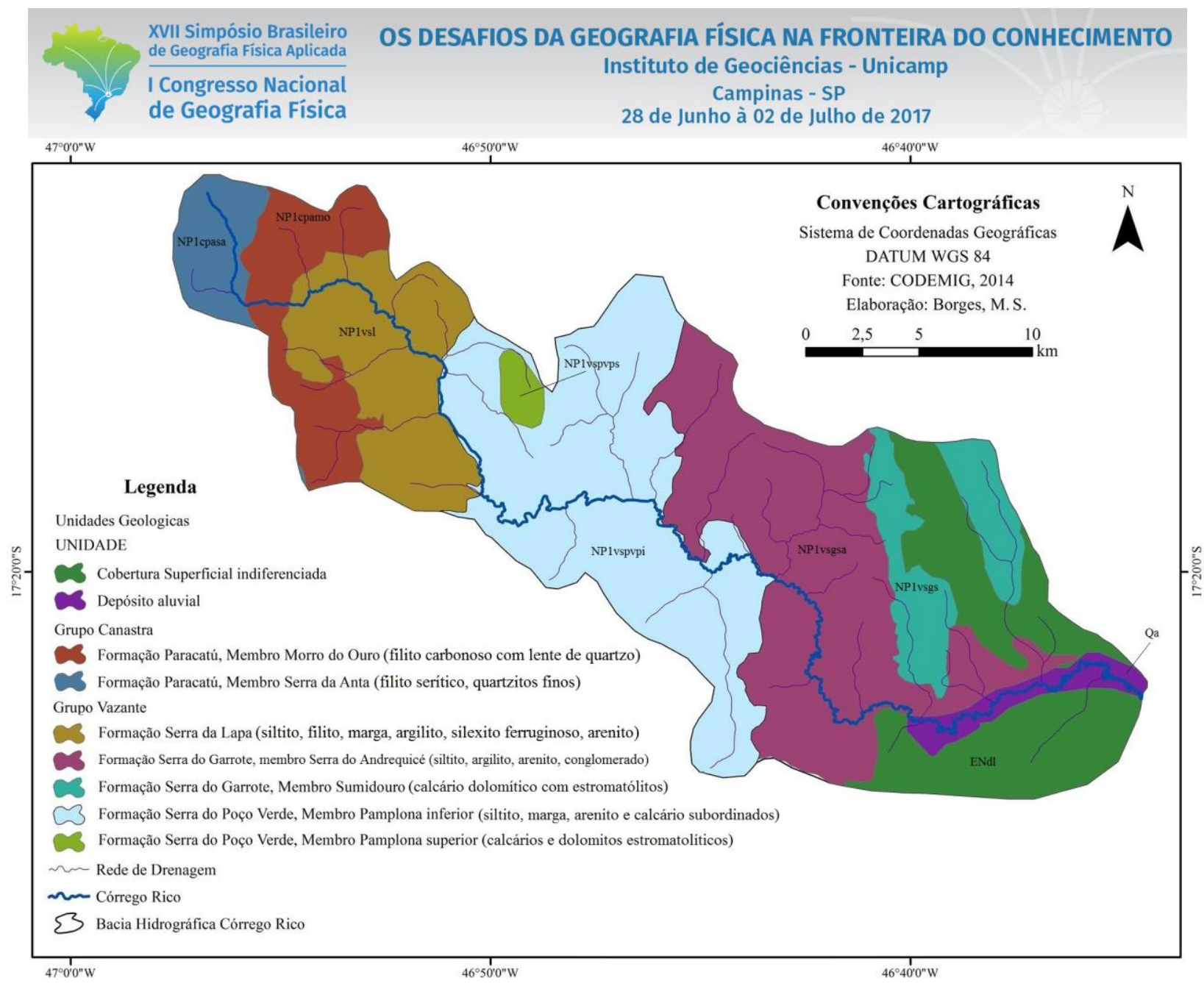

Figura 5: Mapa Geológico do Corrego Rico

Dentre os 51 trechos analisados, 6 deles mostram um Índice SL elevado, que estão distribuídos em diferentes trechos ao longo do canal. Os trechos que apresentaram altos valores do Indice SL são: 14, 17, 21, 30, 37 e 48; sendo que o trecho 37 é a que apresenta maior índice, em seguida do trecho 48, como mostrado na figura 6.

O local que há mais trechos com altos índices SL se dá nas partes do Grupo Vazante, em especial na Formação Serra do Poço Verde, que contém metade desses trechos, sendo eles: 14, 17 e 21. Nele há rochas sedimentares, como arenitos e rochas calcárias que são frágeis se tratando de ações químicas. $\mathrm{O}$ trecho 30 está na Formação Serra do Garrote onde há muitos conglomerados e rochas sedimentares, que também são rochas frágeis.

O ponto 37 apresenta um Índice SL alto, por estar num local de transição de três litologias diferentes, uma do Grupo Vazante, senso elas: Formação Serra do Garrote e as outras duas correspondem à Cobertura Superficial Indiferenciada e Depósitos Aluviais. Já o trecho 48 se localiza na área de Depósitos Aluviais, proximo a foz. 


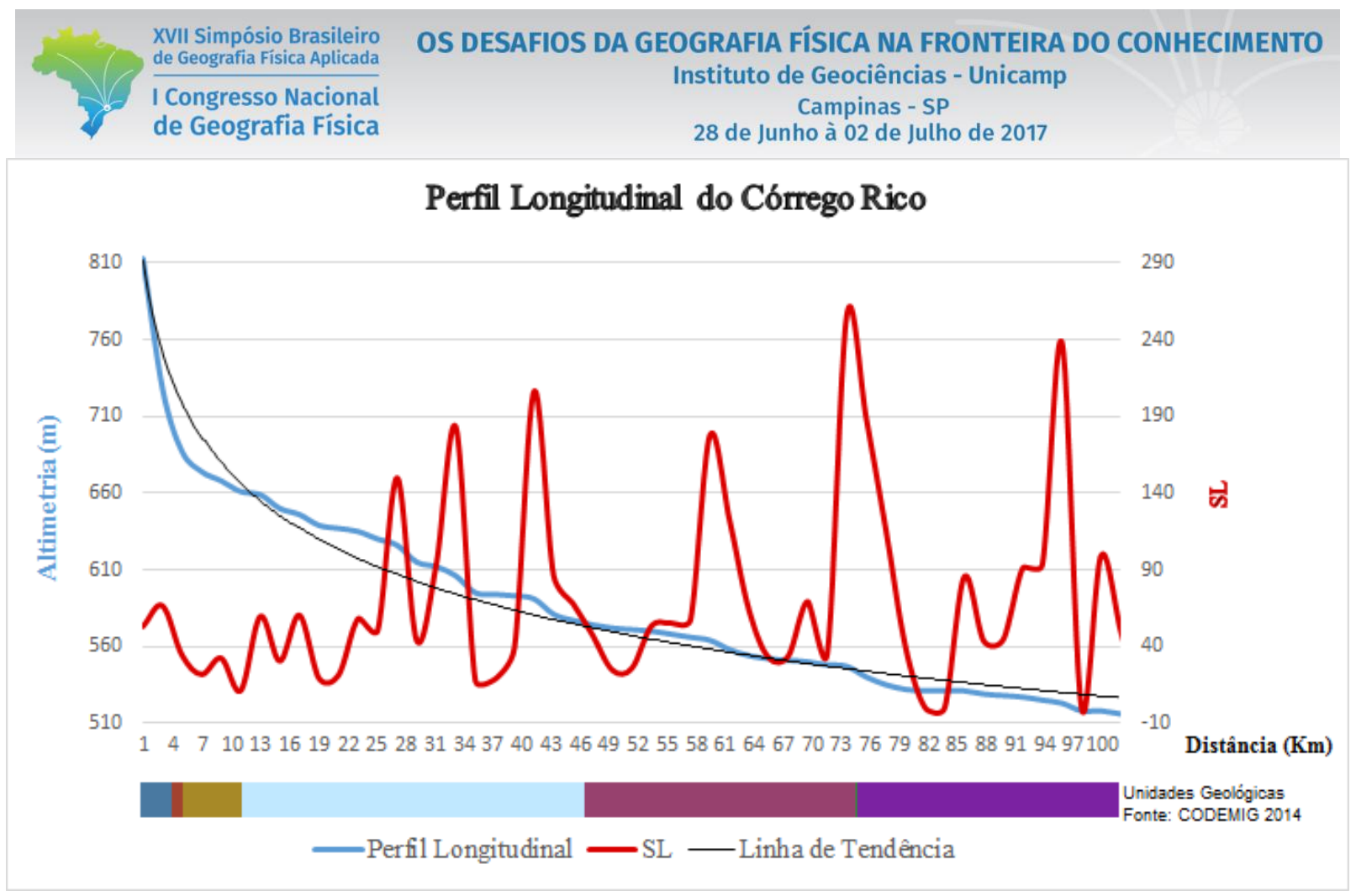

Figura 6: Perfil Longitudinal do Córrego Rico

É interessante notar que dos valores de indice SL encontrados, apresentam-se com maiores da porção mediana para jusante, demonstrando provavelmente uma relação com as variações litológicas. Vale ressaltar que não foi possível verificar se as anomalias também estão relacionadas às estruturas geológicas, como falhas, lineamentos e eixos de dobramentos, justamente por esse trabalho ser apenas de gabinete e não houve campo.

\section{Considerações Finais}

Utilizando o Google Earth na aplicação do Índice de Hack, foi possível identificar as diferênças entre declividade e extenção do canal. O resultado obtidido mostra que, onde há valores elevados do índice SL têm relação com as quedas mais acentuadas do perfil longitudinal. Nas áreas de rochas metamóficas, como esperado, o gradiente é baixo e nas rochas sedimentares são elevadas.

O Índice de Hack aplicado no Google Earth apresenta muitos erros em relação ao perfil longitudinal, o que dificulta a localização de deformações e o local exato delas. Para uma melhor aplicação do índice deve-se utilizar fontes diretas de dados altimétricos de precisão, necessitando ir a campo. O presente trabalho é passível de ajustes sobre a altimetria do terreno para obtenção de valores mais precisos do Índice de Hack. 
Apesar do trabalho apresentar erros topográficos resultantes de falta de precisão dos programas utilizados, ainda foi possível obter o objetivo do estudo, sendo capaz de utiliza-la em sala de aula, no intuito de ensinar técnicas de pesquisa sobre o relevo, além de ser um trabalho de baixo custo.

\section{Agradecimentos}

Agradecemos a todos os colaboradores que ajudaram na elaboração deste trabalho, em especial a FAPEMIG pelo apoio na participação no XVII Simpósio Brasileiro de Geografia Física Aplicada. Agradecemos também aos pesquisadores dos artigos e livros citados no presente trabalho.

\section{Referências}

CASSETI, V. Introdução à Geomorfologia. [s.l.]: 2005. Disponível em:

<http://www.funape.org.br/geomorfologia/>. Acesso em: 14 fev. 2017.

CHRISTOFOLETTI, A. . Geomorfologia. São Paulo: Edgard Blücher, 1980. 188 p.

CHRISTOFOLETTI, A. . Geomorfologia Fluvial. São Paulo: Edgard Blücher, 1981. 313 p.

CODEMIG - Companhia de Desenvolvimento Econômico de Minas Gerais. Mapa Geológico do Estado de Minas Gerais. Belo Horizonte: CODEMIG, 2014. Escala 1:1. 000.000.

COOLEY, S.W. Hack's Stream-Length. [s.1] 2015. Disponível em: <http://gis4geomorphology.com/hacks-streamlength/>. Acesso em: 03 fev. 2017.

CUNHA, S.B.; GUERRA, A.J.T (Org.). Geomorfologia do Brasil. 6a Edição. Rio de Janeiro: Bertrand Brasil, 2010. $390 \mathrm{p}$.

ETCHEBEHERE, M. L. C. ; SAAD, A. R. ; PERINOTTO, J. A. J. ; FULFARO, V. J. . Aplicação do Índice "Relação Declividade-Extensão - RDE" na Bacia do Rio do Peixe (SP) para detecção de deformações neotectônicas. Revista do Instituto de Geociências - USP - Série Científica, São Paulo, v. 4, n. 2, p. 43-56, 2004.

HACK, J. T. Interpretation of Erosional Topography in Humid-Temperate Regions. Amer. Journ. Sci, New Haven, Conn. v. 258-A, 1960.

HACK, J. T. Stream-profile analysis and stream-gradient index. Journal of Research of the United States Geological Survey, v. 1, n. 4, p. 421-429, 1973.

MARQUES, J. S. (Org.). Ciência Geomorfológica. Geomorfolgia: Uma Atualização de Bases e Conceitos, $12^{\mathrm{a}}$ ed. Rio de Janeiro, Bertrand Brasil, p. 23-50, 2013.

PENTEADO, M.M. Fundamentos de Geomorfologia. Rio de Janeiro: IBGE, 1983. p. 1-10.

POLZIN, M. A. Análise da Aplicação do Método de Hack no Estudo Geomorfológico em Afluentes do Curso Superior da Bacia Hidrográfica do Itapocu - SC - Brasil. Geografia: Ensino \& Pesquisa, Santa Maria, v. 1 2, n. 2, p 59 - 66, 2008

SOUZA, D. V. ; MARTINS, A. A. : FARIA, A. L .L. Aplicação do Índice de Hack (SL) a Um Trecho do Rio Zêzere, Portugal. Revista Brasileira de Geomorfologia, v. 12, n. 1, 2011. 